\title{
The Curious Case of Reconstruction in Syntax
}

\author{
Spike Gildea, Eugenio R. Luján and Jóhanna Barðdal
}

\begin{abstract}
The general consensus in the historical linguistics community for the last half a century or so has been that syntactic reconstruction is a bootless and unsuccessful venture. However, this view has slowly but steadily been changing among historical linguists, typologists, and anthropological linguists alike. More and more syntactic reconstructions are being published by respectable and virtuous publication venues. The debate on the viability of syntactic reconstruction, however, continues, and issues like i) lack of cognates, ii) lack of arbitrariness in syntax, iii) lack of directionality in syntactic change, iv) lack of continuous transmission from one generation to the next, and v) lack of form-meaning correspondences have, drop by drop, been argued not to be problematic for syntactic reconstruction. The present volume contributes to two of these issues in detail; first the issue of reliably identifying cognates in syntax and second, the issue of directionality in syntactic change. A systematic program is suggested for identifying cognates in syntax, which by definition is a different enterprise from identifying cognates in phonology or morphology. Examples are given from several different language families: Indo-European, Semitic, Austronesian, Jê, Cariban, and Chibchan. Regarding the issue of directionality for syntactic reconstruction, most of the studies in this volume also demonstrate how local directionality may be identified with the aid of different types of morphosyntactic flags, particularly showcased with examples from Chibchan, Semitic, and various Indo-European languages.
\end{abstract}

Why a Volume on Reconstructing Syntax

In the field of historical-comparative linguistics, the enterprise of reconstruction has first and foremost been focused on lexical, morphological and phonological comparisons, while syntactic reconstruction has been regarded as bootless, frowned upon and even lambasted (cf. Watkins 1964; Jeffers 1976; Lightfoot 1979, 2006; Harrison 2003; Pires \& Thomason 2008; von Mengden 2008, inter alia). The rationale behind this position stems from the view that syntactic units are radically different from, for instance, morphological and lexical units. There is, of course, no doubt that syntactic structures are 
larger and more complex than most morphological structures and phonological units, and at first sight they may certainly appear as ontologically different from word units. In other words, while morphological and lexical units are considered as having their own meaning, the traditional view of syntax is that it is not inherently meaningful. Rather, the meaning of sentences is more often than not taken to be the sum of the meaning of the lexical parts that instantiate them (cf. Klein 2010). Due to this semantic compositionality, reconstruction based on arbitrary form-meaning correspondences has been systematically ruled out. Further arguments against syntactic reconstruction are that syntactic structures are not inherited in the same manner as the vocabulary is (Lightfoot 1979, inter alia), that cognates cannot be identified in syntax (Jeffers 1976; at least with the same confidence as in the lexicon, Walkden 2009, 2013), that syntactic change is not regular, as opposed to the regularity of phonological change (Lightfoot 2002a; Pires \& Thomason 2008), and that there is no arbitrariness found in syntax (Harrison 2003). The consensus based on these objections is, and has been, that syntactic reconstruction is either ontologically impossible or at the least substantially less certain than phonological and morphological reconstruction.

However, alongside these attacks, research exists within historicalcomparative syntax suggesting that these critiques are overly pessimistic. To begin with, the arbitrariness requirement is simply not needed in syntax, as its primary function within the Comparative Method is to determine genetic relatedness; thus, if one limits syntactic reconstruction to languages known to be genetically related, this critique becomes orthogonal (Harrison 2003; Barðdal \& Eythórsson 2012a; Barðdal 2013, 2014). Turning to the issue of cognacy, a growing number of studies within multiple theoretical perspectives identify cognates also in syntax, including Harris (1985, 2008), Campbell (1998), Bowern (2008), Barðdal \& Eythórsson (2012a-b), Willis (2011), Dunn et al. (2017), Pooth et al. (2019), and many more studies cited in Section 3.4.

With regard to regularity of syntactic change, there are multiple considerations to take into account. First, we question the accuracy of the absolutist rhetoric surrounding the alleged regularity of sound change: in fact, there are many less regular sound changes that have simply been excluded from the definition of sound laws (Hoenigswald 1978); for example, no relevance has been accorded to irregular phonetic reduction or erosion associated with grammaticalization processes (Heine \& Kuteva 2004: 2-3, 9). Also, the primary function of sound laws in historical linguistics is that they stand in for a similarity metric when deciding upon cognate status (Harrison 2003). However, historical linguists have always relied heavily on context, rather than on absolute sound laws, in determining which specific sound changes are more and less plausible 
for each specific reconstruction (a point made nicely by Seržant 2015: 121). The same should be true of syntax, with directionality of change not being required to follow from absolutist principles, but rather being extrapolated from attested changes to analogous constructions in analogous contexts.

Under the assumption that syntactic reconstruction is indeed possible, two of the three co-editors of this volume proposed a workshop at the 2011 International Conference of Historical Linguistics, entitled Reconstructing Syntax. The goal of this workshop was to address fundamental issues of reconstruction in general and syntactic reconstruction in particular, either via individual case studies of syntactic reconstruction from different languages and language families or via a comparison of how different theoretical frameworks might contribute to improving the methodology for syntactic reconstruction. The workshop attracted a relatively balanced mix of theoretical papers, case studies from Indo-European, and case studies from other parts of the world. Inspired by that workshop, this volume focuses on two primary topics: (i) how to identify syntactic cognates, and (ii) departing from attested syntactic cognates, how to identify the most likely direction of change, which in turn allows for reconstruction from these cognates to the source syntax in a given protolanguage. In addition to this introduction, this volume contains four papers presented at that workshop, supplemented by four more papers collected or commissioned afterwards.

The remainder of this chapter is organized as follows. In Section 2, we review some of the problems - beyond identification of cognates and determination of directionality - that have been claimed as obstacles to the reconstruction of syntax. Section 3 surveys several approaches, both early and more current, to syntactic reconstruction. From this background, Section 4 explicitly addresses the viability of establishing, in the domain of syntax, what we believe to be the two critical foundations of comparative reconstruction: identification of cognates (Section 4.1) and determination of direction of change (Section 4.2). Finally, in Section 5, we introduce the chapters of this volume and highlight how each contributes to our understanding of one or both of these primary issues.

\section{Some Perceived Limits and Problems of Syntactic Reconstruction}

We begin with the observation that, in many general overviews of the comparative method and in comprehensive presentations of proto-languages, no reference at all is found to the possibility of syntactic reconstruction. If, as a representative case study, one probes into the more than two centuries old 
tradition of scholarship on Proto-Indo-European, one notices that the attention paid to syntax is scanty in comparison to the great quantity of studies devoted to investigating other aspects of the proto-language. Among the recent presentations of Proto-Indo-European, Szemerényi (1996) and Beekes (2011) do not even have chapters on syntax, while Fortson (2004) devotes significantly less space to syntax than to phonology or morphology, without explicitly discussing the methodology of syntactic reconstruction. Similarly, in his chapter on methods in reconstruction in a recent handbook on Indo-European, Krasukhin (2017) deals with phonological, morphological, and lexical reconstruction, but there is no section on syntactic reconstruction. In contrast, Bowern $(2017: 4,7)$, in the first chapter of the same handbook, explicitly acknowledges that the comparative method can be applied to syntax and systematic correspondences in various domains (including syntax) are needed in order to prove genetic relatedness among languages.

Even though, as laid out by Harris \& Campbell (1995: 16-35), the Neogrammarians did devote some attention to reconstruction of syntax alongside morphology and phonology, in the words of Barðdal \& Gildea (2015: 3):

... there was a major difference in the results of [the neogrammarians'] work, in that for phonology they proceeded to develop and rigorously test a methodology for reconstruction that has remained largely unchanged as the modern Comparative Method. In contrast, for morphosyntax, they did not consolidate their individual works into a coherent, consistent methodology, and so they did not produce similarly large-scale reconstructions of PIE [Proto-Indo-European] syntax.

On the most conservative approach, one might try to reconstruct actual utterances or strings of words that the speakers of a proto-language might have used at a certain point. However, a program of that kind would be doomed to failure: scholars like Keydana (2018: 2195) state that after 200 years of comparative work on Indo-European languages, probably no other phrase can be reconstructed with certainty for Proto-Indo-European (PIE) than VP * eg whent og whim 'he killed (the) snake' (Watkins 1995: 301). Although to this list one might add the well-known formulaic NP *Klewos no ${ }^{h}{ }^{h}{ }^{w h}$ itom 'unperishable glory' (first pointed out by Kuhn 1853: 467) and perhaps others (for efforts, cf. Clackson 2007: 180-184, with further references), this type of reconstruction would lack much linguistic interest. This is because a grammar, whether diachronic or synchronic, is not a collection of sentences, but a nuanced description of the patterns and rules that characterize the utterances in a language. Daniels (2020) makes this point cogently, framing the task of reconstruction as 
one suited for types as opposed to tokens, a perspective equally necessary for the reconstruction of lexicon and of syntax.

One criticism against syntactic reconstruction has to do with the fact that it is not a "first-order" reconstruction, as Clackson (2007: 158-159) formulates it. As framed by Clackson, in contrast to establishing sets of cognates in phonology, which by itself provides the basis for claiming genetic relationship between two languages, syntactic reconstruction would be a "second-order" operation that relies on previous knowledge of genetic relatedness and seeks to explain the data in the descendant languages starting from the reconstructed pattern in the proto-language, with special attention to archaisms and oldest attested forms. On the one hand, we do not dispute that the reconstruction of abstract syntactic patterns should not be the sole basis for claiming genetic relatedness between two languages and we find strong support for this position in the persuasive discussion in Dybo \& Starostin (2008: 124-138).

On the other hand, it is far from a consensus position that the sole basis for claiming genetic relatedness between languages is via establishing lexical cognates with phonological correspondences. Many studies that address controversy in demonstrating genetic relatedness focus on the importance of identifying idiosyncratic morphological behavior of the sort that is unlikely to be borrowed, and that hence can be taken as evidence for shared retention from a common proto-language. In an acrimonious debate on precisely how to determine relatedness among the languages of the Americas, the importance of such evidence is about the only point on which Greenberg and his detractors agree, cf. Greenberg (1957: 37-38, 1987: 30, 1989: 108-109), Campbell (1988, 2003: 268-270), Rankin (1992); Dixon (1997: 22), Campbell \& Poser (2008). Similarly, the most convincing argument for the Dene-Yeniseian hypothesis derives less from the limited number of lexical cognates identified so far, with their tentative phonological correspondences, but rather from the fact that "Shared Dene-Yeniseian morphological structures have been identified across every major lexical subsystem." (Vajda 2018: 281). Regardless, this issue is clearly orthogonal to the question of whether syntax can be reconstructed, since at its strongest, Clackson's concern merely restricts the enterprise of syntactic reconstruction to previously established genetic families.

We also take issue with Clackson's view of syntactic reconstruction as being a "second-order operation", i.e. as only existing in order to seek explanation for the data in the daughter languages, starting from the reconstructed pattern in the proto-language. Quite the reverse, this would involve "diachronic interpretation" in the sense of Klimov (1977), as opposed to a proper syntactic reconstruction of the linguistic situation in a proto-stage, based on the syntactic evidence from the daughters. In contrast to Clackson's view, Ferraresi \& 
Goldbach (2008: 9) point out that syntactic reconstruction has two main functions, namely i) to reconstruct a viable language supposedly spoken in the past, and ii) to better understand the general processes of language change. To this, Eythórsson \& Barðdal (2016: 97) add a further goal, iii) to model the grammar of a proto-stage, adequately reflecting the state-of-the-art of the historical linguistics community's knowledge at each time. Otherwise, a reconstruction limited to a selection of the language system, in this case phonology, morphology and lexis, will not produce an accurate picture of the grammar as a whole for the relevant proto-stage.

Moreover, several studies of syntactic reconstruction have seen the light of day in recent years, none of which takes the situation in the proto-stage as its point of departure, aiming to explain the development from the proto-stage to the daughters. Instead, all these studies take the situation in the daughter languages as the point of departure and reconstruct syntactic constructions of the proto-stage, thus being first-order operations in Clackson's terminology, despite the fact that they involve syntactic reconstruction.

A further methodological critique against syntactic reconstruction raised in the literature has to do with the risk of misinterpreting syntactic variation, based on the assertion that syntactic variation can be due, with a significantly higher frequency than in other language domains, to style, register, or sociolinguistic level. For example, Hock (2000) draws attention to the impact of genres and literary styles on syntax, which might lead to the misanalysis of stylistic variation as diachronic variation. From this perspective, when reconstructing syntax, one should consider whether in proto-languages or in earlier unattested stages of languages, topicalization and fronting would have occurred as a way of emphasizing or highlighting a given element, beyond being mandatory in certain constructions (e.g. typically in relative clauses in many languages) or being characteristic of certain impressive modalities (see, among others, Watkins 1976; Hale 1987; Justus 1993, 2000 for Proto-Indo-European).

This criticism may be valid for both traditional and generative approaches to word order. On a constructional approach to syntactic reconstruction, however, criticism of this type is less compelling as, on a constructional view, variation in word order can never be a matter of simple frequencies nor of stylistic or register variation. Instead, variation in word order represents different constructions with different information-structural properties, as such constituting form-meaning pairings of their own, which are by definition the comparanda of the Comparative Method.

A successful syntactic reconstruction of the type described above, indeed carried out for Proto-Indo-European and involving fronting to clause initial position, is Barðdal et al.'s (2013) study on the adversative use of 'woe', based 
on data occurring in five different archaic Indo-European daughter languages. Two different word orders are consistently found across the daughters, of which one is analyzed as representing neutral word order and the other as involving focus fronting, more specifically predicate fronting of focused material. As a consequence, Barðdal et al. (2013) reconstruct both neutral word order and a clause-initial focus construction for the relevant proto-stage, in this case, Proto-Indo-European.

A further problem for syntactic reconstruction, pointed out by Lightfoot (1979, inter alia), relates to the acquisition of syntax, as opposed to the acquisition of lexis. Lightfoot argues that children do not acquire syntax in the same way as they acquire words in that words are transmitted from one generation to the next, while syntactic rules are not. Instead, according to Lightfoot, syntactic rules are deduced by children on the basis of the grammar that they are exposed to. This means that, on Lightfoot's approach, there is a fundamental difference between words and syntax, which in turn excludes the reconstructability of syntactic structures.

We, as a matter of fact, call this lexis-syntax dichotomy into question. As repeatedly argued by Barðdal and Eythórsson (Barðdal \& Eythórsson 2012a; Barðdal 2013, 2014; Eythórsson \& Barðdal 2016), this view is a gross oversimplification of how children acquire words. Contrary to Lightfoot's view, words are also abstractions, i.e. they are form-meaning correspondences that are also deduced on the basis of the input children are exposed to (cf. Adger 2003; Tomasello 2003). Therefore, both in the case of acquisition of lexical material and syntactic objects, children have to abstract; either they have to build up their vocabulary, or they have to build up their grammar, in both cases on the basis of the input they are exposed to. There is no doubt, however, that on Lightfoot's conception of syntax as consisting of abstract rules, there is little basis for identifying analogy between lexis and syntax. On a construction grammar account, in contrast, the distinction between words and morphosyntax is not a matter of kind, but more a matter of degree (cf. Section 3.4 below).

A somewhat bigger-picture critique of syntactic reconstruction is that one cannot theoretically aim to reconstruct the whole grammar of a protolanguage or of a non-attested, earlier stage of a language. Of course, one will never be able to determine the whole set of syntactic rules for any given protolanguage - only a partial knowledge will ever be accessible through syntactic reconstruction. As articulated by Gildea (2002: 320), "when reconstructing grammar, one is limited to reconstructing morphology and syntactic systems on the basis of the surviving morphology and morphosyntactic systems. One can never be confident in reconstructing a complete picture of all the 
grammatical resources of a proto-language because one never knows what pieces might have disappeared altogether, leaving no reflexes in any modern language." However, this is a practical limit based on what grammatical patterns have survived in daughter languages, not an a priori constraint on the types of grammatical patterns that may be reconstructed. Similar limits to phonological or morphological reconstructions have not prevented scholars from trying to gain insights into the past based on attested phonological and morphological systems; hence, the existence of limitations is no reason to eschew recovering also whatever elements of syntax may be reconstructed.

Hale (2007: 228) defines a reconstructed proto-language as a "set of all (chronologically) anterior grammars which do not differ in recoverable features." This explicitly points out that the unique, specific, complete grammar of the proto-language may not be accessible through reconstruction, but it is possible to approximate it by retrieving a number of features through comparison between the attested grammars of the descendant languages. For example, given that syntagmatic relations are produced in praesentia, the occurrence of a given element may trigger, allow or prevent the presence of another element that is syntactically linked to it. On this view, reconstructed syntax will be much more abstract than reconstructed phonemes or meaningful sequences of phonemes, basically consisting only of combination rules between linguistic elements that may or must co-occur with each other, such as agreement, dependency marking, word order, or the like.

From this perspective, syntactic rules are abstract and thus should be fleshed out in perceptible morphological elements or linearity rules in discourse (i.e., word order); they would otherwise fail to surface in the actual linguistic productions and would, therefore, be impossible to grasp. On the one hand, we see this as an epistemological problem that follows from the mechanisms of theories that represent syntax in the form of deep structures, which are themselves abstractions from patterns in the data. It seems clear that one cannot reconstruct such abstractions, but that rather what must be done is to reconstruct the actual pronounceable morphosyntactic patterns; if one then wishes to posit abstract rules from these reconstructed patterns (using the same methodology as for synchronic analysis), there would be a comparable empirical basis for the analysis (Campbell 1987: 91; cf. also Gildea's 2000: 68 articulation of a concrete example of this issue, asserting the difficulty in reconstructing abstractions like "basic word order" or "order in deep structures"). Of course, one might step away from this problem altogether by utilizing theories whose representations are more closely tied to concrete, surface representations. From such a perspective, the compound notion of "morphosyntax", 
however formalized (or even relatively unformalized) is readily reconstructable (cf. Section 3.4).

Despite the disagreements above, we largely agree with Clackson's (2007: 159) summary of the relevant requirements in a list of three prerequisites that must be met when attempting syntactic reconstruction - his list validates our concern in this volume, as (a-b) are prerequisites to establishing cognates and

(c) is the basis of establishing directionality.

a) Enough evidence of the construction must be available in the earliest phases of the languages as the basis for the reconstruction and languagespecific developments must be ruled out before

b) Instances of the construction in the sister languages must share one or more comparable element (word-order, agreement, morphology or lexical particles)

c) The development from the reconstructed construction to the ones actually occurring in the daughter languages can be accounted for in terms of a well-known process of syntactic change

We now turn to a brief survey of approaches that have been taken to syntactic reconstruction, which in turn contextualize our position on resolving the problems of cognacy and directionality.

\section{$3 \quad$ Approaches to Syntactic Reconstruction}

We start with a concise recapitulation of the Neo-Grammarian view of syntactic reconstruction (Section 3.1), before proceeding to the typological approach (Section 3.2), the generative approach (Section 3.3) and finally concluding the discussion with a summary of the advantages of a constructional approach to syntactic reconstruction (Section 3.4).

\subsection{The Neo-Grammarian Approach to Syntactic Reconstruction}

The Neo-Grammarians were first and foremost focused on comparative work within the areas of phonology, morphology and lexis, developing a comparative methodology to be used for reconstruction involving data from these subfields (see the overview in Eythórsson \& Barðdal 2016). Their proposed methodology has more or less withstood the test of time, well known today as the Comparative Method. This methodology involves several procedural steps, including i) identifying cognates, ii) setting up correspondence sets, iii) choosing between different alternants of the relevant correspondence sets (with the aid of the sound laws), and iv) putting forward reconstructed sounds, 
morphological forms or words, based on the chosen alternants of the correspondence sets and the directionality of the assumed change.

Neither the Neo-Grammarians nor the structuralists for that matter had much to say on syntax or syntactic reconstruction. The reason is most likely their lack of adequate tools to deal with syntax and syntactic variation; or in other words, their lack of syntactic theory (Fox 1995: 104). However, the Neo-Grammarians certainly made some important observations on syntactic and morphosyntactic matters, even though their stringent methodology did not carry over to the field of syntax.

One of the major contributions to syntax at the time of theNeo-Grammarians is Wackernagel's (1892) insights concerning the placement of enclitics in the second position of the sentence. The same is true of Delbrück's (1878) work on the position of the verb in Vedic and the other early Indo-European languages. Both Delbrück (1907) and Havers (1911) also worked on the function of the morphological cases in the early Indo-European languages. Some comprehensive comparative work on the syntactic properties of mood and modal categories started with the work of Jolly (1872), Thurneysen (1885) and Delbrück (18931900 ), to mention only a few of the syntactic topics that the Neo-Grammarians were concerned with.

One topic, in particular, of interest to the Neo-Grammarians around the turn of the 19th and the 2oth centuries, was the reconstruction of an ergative alignment system for Proto-Indo-European. Early scholars like Uhlenbeck (1901), Pedersen (1907) and Vaillant (1936) argued for such a reconstruction on the basis of what appears to be a split system with nouns lower in the animacy hierarchy, i.e., neuters, lacking a morphological opposition between nominative and accusative, with the only exception of Hittite, which has an ergative marker - $a n z(a)$ for neuters when they are the subject of a transitive verb. This early reconstruction of Proto-Indo-European being an ergative language was later challenged (Villar 1983; Rumsey 1987a, 1987b), preceding a new wave of scholarship where it has been proposed that Proto-Indo-European was a stative-active language (Gamkrelidze \& Ivanov 1995; Lehmann 1993; Bauer 2000 , inter alia). This debate is indeed still ongoing, cf. recent work by Willi (2018) and Pooth et al. (2019).

In sum, the Neo-Grammarian approach to syntactic reconstruction was that it was "essentially the study of the function of forms" (Penney 2000: 35). This position was based on the precedence of morphology over syntax and any syntactic reconstruction was dependent on an a priori morphological reconstruction. That is, after reconstructing a given morphological category, the next step was to determine which of the meanings or functions associated with those categories were present in the proto-language. In the domain of nominal 
morphosyntax, this involves number, gender and, especially, case, while in the domain of verbal morphosyntax, person, number and, especially, voice, tense and aspect. The goal to uncover the meanings and/or functions of morphosyntactic categories was achieved by studying the uses of those categories in the older Indo-European languages, especially Greek and the Indo-Iranian languages (a modern statement of this position would be, e.g., Serzant 2015).

\subsection{Typological, Holistic Approaches to Syntactic Reconstruction}

A radical methodological turn took place in the 1970's when Lehmann (1974) made an attempt to apply Greenberg's (1966) findings on implicational universals of word order to syntactic reconstruction (see overview in Eythórsson \& Barðdal 2016). Lehmann was primarily concerned with basic word order and its implications for the order of other elements in the clause. The main goal of this endeavor was to determine whether the proto-language was OV or VO. A number of studies following Lehmann include Friedrich (1975) and Miller (1975), also reconstructing basic word order for Proto-Indo-European.

However, Friedrich and Miller proposed a radically different reconstruction from Lehmann and from one another. Lehmann argued that Proto-Indo-European was an sov language, Friedrich that it was an svo language, and Miller that the basic word order was sov, svo and vso. The reason that these reconstructions are 18 o degrees different is due to differences in the material on the basis of which these reconstructions are made.

The flaws of holistic typological approaches to syntactic reconstruction, i.e. approaches based on implicational relations between properties, were immediately pointed out in an influential article by Watkins (1976), who expressed severe critique of the typological approaches to reconstruction of Proto-Indo-European syntax, carried out by Lehmann, Friedrich and Miller, going as far as labeling these efforts a "pseudo-problem". Watkins' criticism was later iterated by scholars like Jeffers (1976), Lightfoot (1979) and Winter (1984). Since then, the holistic typological approach to syntactic reconstruction, based on implicational relations between properties, has been more or less debunked by the scholarly community (Hale 1987; Mendoza 1998; Drinka 1999; Gildea 2000; Wichmann 2008; Barðdal \& Eythórsson 2012a).

In connection to this, another interesting point of discussion is the use of "residues" or "relic constructions", i.e. archaisms, when reconstructing syntax. Irregular and synchronically unanalyzable patterns have played an important role in reconstructing morphology; similarly, one can detect irregular, marginal syntactic constructions that do not fit so well in the more general rules of a language at a given stage and might therefore be considered a relic of a previous stage at which they were regular. Campbell (1986: 81-86) has an insightful 
discussion of this principle, with the examples of Balto-Finnic infinitives and participial subjects. Lehmann $(1993,1994)$ resorted frequently to alleged residues or relics of the original active structure of PIE that he reconstructed. However, Viti (2015) warns about either applying the anomaly principle or using consistency in the descendant languages as a basis for the reconstruction of a proto-language - both are problematic, she argues, due to the uncertain status of syntactic variation (cf. Section 2).

\subsection{Generative Approaches to Syntactic Reconstruction}

After the Neo-Grammarians and the structuralists, and in the era of modern linguistics, in particular generative linguistics, the focus of research has been on synchronic structures, with historical and comparative approaches to language being disfavored. The first important contribution to historical syntax from this perspective was Lightfoot's (1979) book where he explicitly rejects the possibility of syntactic reconstruction, given that in his view syntactic change is basically a matter of reanalysis, a process lacking any inherent directionality, which, in turn, prevents the recovery of any prior stages (1979: 154-166, 1980, 1999: 255-257, 2002a: 114-130). As we argue below (Section 4.2), directionality can indeed be detected for each case of reanalysis per se, debunking the claim (and calling into question the theoretical postulates that informed it).

More recent approaches to historical syntax within the generative paradigm have been positively inclined towards the possibility of reconstructing syntax (see Eythórsson \& Barðdal 2016 for an overview). For instance, Hale (1987) and Garrett (1990) reconstruct the position of clitics in the hierarchical Proto-Indo-European clause structure, focusing in particular on the Wackernagel position. Roberts (2007: $363-367)$ also argues that parameters, which are conceptualized as formal features of lexical entries, can be taken as the comparable units required by the comparative method. Examples are Roberts' reconstructions of the null-subject parameter, the OV/VO basic wordorder or $w h$-movement in interrogatives and relatives for Proto-Indo-European. No reanalysis would be needed on this approach.

More recently, scholars from within the generative paradigm, like Willis and Walkden, have successfully carried out syntactic reconstructions (Willis 2011; Walkden 2009, 2013, 2014). A particularly important contribution is Willis's (2011) research on the distinction between "universal directionality" and "local directionality". The former relies on extensive comparisons across languages that allow for identifying widespread tendencies in language change. The latter, in contrast, underlines the weight that should be accorded to the data under each analysis, as these undoubtedly call for specific interpretations, providing the basis for identifying the directionality of change, and thus contributing to 
a syntactic reconstruction. Hence, Willis concludes, local directionality is all that is needed for identifying prior stages of languages, even if we never determine any kind of universal directionality.

One major problem for generative approaches to syntactic reconstruction, as pointed out by Eythórsson \& Barðdal (2016), is that within the generative paradigm, there is no natural place for semantics, hence strictly speaking no reconstructions can take place on the basis of form-meaning correspondences within that framework. Generative scholars are forced to either base their reconstructions on form alone, or they may indeed take meaning or function into account, despite the lack of natural space for meaning or function in their formalisms. As such, generative scholars have to go beyond the limits of their own frameworks in order to contribute to syntactic reconstructions.

\subsection{Constructional Approaches to Syntactic Reconstruction}

Despite the pessimistic voices of the scholars of the 1970's, such as Watkins (1976), Jeffers (1976) and Lightfoot $(1979,1980$ ) (see Section 3.2 above) a new generation of historical linguists emerged, more specifically, historical syntacticians, eager to address the challenges of historical syntax, including the more-or-less stranded endeavor of syntactic reconstruction. In particular, Harris (1985) and Harris \& Campbell (1995) introduced into the field the notion of syntactic pattern and developed a rigorous research program based on this concept of how to reconstruct syntax. Gildea $(1992,1998,2000)$ soon followed in their footsteps, putting forward a reconstruction of the Proto-Cariban verbal system (including multiple alignment properties), as well as reconstructing the nonverbal origins of six additional clause types found in the modern Cariban languages. Key to these reconstructions were the identification of the cognate structures that composed each innovative clause type plus providing local arguments for directionality of change, and thereby deducing the reconstructable source. Independent of this enterprise, Kikusawa (2002, 2003), working on alignment changes in Proto-Central-Pacific, launched the concept of cognate structures, applying it to basic word order constructions, as a part of a larger program of establishing correspondence sets in syntax. Through the efforts of these scholars, huge advances have been made in the methodology of reconstruction of syntax.

Inherent in the approaches of Harris, Campbell, Gildea and Kikusawa is the preconception of a construction, i.e. aform-meaning pairing, which indeed is the comparanda of the Comparative Method, as laid out by the Neo-Grammarians (see Section 3.1 above). It has also been pointed out by scholars working within the framework of Diachronic Construction Grammar, i.e. scholars who apply constructional analysis on historical data, that Construction Grammar is more 
easily extendible to syntactic reconstruction than other linguistic models, due to the basic status of form-meaning pairings in that framework (cf. Eythórsson \& Barðdal 2011, 2016; Barðdal \& Eythórsson 2012a-b; Barðdal 2013, 2014; Barðdal \& Gildea 2015; Daniels 2015, 2017, 2020).

That is, constructions are assumed to be the basic building blocks of language and are as such form-meaning pairings (Goldberg 1995, 2006; Croft 2001; Michaelis \& Ruppenhofer 2001; Boas 2003; Fried \& Östman 2005, inter alia). On a Construction Grammar approach, constructions exist at all levels of language, at the level of morpheme, word, phrase, as well as at the level of larger syntactic units like argument structures and clause structure, yet maintaining their status as form-meaning pairings. Constructions also range from being concrete lexically filled units, like words, to being partly lexically filled set phrases and idioms, to being almost or entirely schematic (Lakoff 1987; Fillmore, Kay \& O'Connor 1988; Nunberg, Sag \& Wasow 1994; Goldberg 1995; Jackendoff 1997, inter alia), but at all times maintaining their status as form-meaning pairings. In other words, the representational formalism of Construction Grammar, explicitly identifying and linking both form and meaning, can be equally well applied to all linguistic material. From this basic assumption of Construction Grammar, reconstructing syntax not only becomes a practical exercise in historical linguistics, but also a viable and a realistic undertaking when studying the history of languages.

In order to illustrate this point, consider the findings of Barðdal et al. (2013) where the linguistic history of woe in the Indo-European languages is investigated. This Indo-European adverb 'woe' builds a part of an argument structure construction found with a compositional predicate involving a dative subject and the verb 'be' confined to 3 rd person singular. A comparison of the relevant data, stemming from five different Indo-European subbranches, Germanic, Baltic, Slavic, Italic and Indo-Iranian, reveals three different but clearly related constructions, i) 'woe', ii) 'woe'-DAT and iii) DAT-'is-woe'. The first construction is analyzed as having an exclamative function, while the third construction is analyzed as a predicative construction with the pragmatic function of expressing speaker's dismay (used first and foremost in situations of adversity). The second construction is analyzed as a 'be' less variant of the predicative construction, an analysis that requires an explanation of the difference in word order between the two.

Barðdal et al. (2013) reconstruct both the first construction, 'woe', and the second construction, 'woe'-DAT, as exclamative constructions, but the internal structure of the second is inherited from the predicative construction, DAT-'is-woe' - the verb 'be' is omitted and 'woe' occurs in first position due to 
focus fronting of the predicate. This analysis is based on instances in the early daughter languages where focused material indeed occurs in first position, ultimately preceding the subject. As a result, Barðdal et al. (2013) reconstruct neutral word order for Proto-Indo-European (the relative position of the subject and the predicate), as well as a clause-initial focus position for that same language. This research was successfully carried out through a proper analysis of the meaning/function of the three constructions, formalized with the box formalism of Construction Grammar, which includes fields for both form and function.

Further syntactic reconstructions carried out via this formalism in Construction Grammar include the reconstruction of grammatical relations for Proto-Germanic (Barðdal \& Eythórsson 2012b; Eythórsson \& Barðdal 2016), different levels of schematicity of the ditransitive construction in Proto-Germanic (Vázquez-González \& Barðdal 2019), a non-finite (gerundive) modal construction for Proto-Indo-European (Danesi et al. 2017), oblique subject constructions for Proto-Indo-European (Barðdal \& Smitherman 2013; Barðdal et al. 2013; Johnson et al. 2019), as well as the reconstruction of a verb-class specific argument structure constructions for verbs of success in Proto-Indo-European and the conceptual metaphor motivating this argument structure in the minds of Proto-Indo-European speakers (Johnson et al. 2019).

We turn now to the questions that motivate this collection.

\section{The Comparative Method and Syntactic Reconstruction}

In this section, we take the position that the comparative method is equally adequate to the reconstruction of syntax as it is to the reconstruction of phonology and morphology; it is merely different because the domain of investigation has different properties. We suggest that the theoretical definition of cognates (i.e., "what they are") is independent of the operational definition (i.e., "how to know one when you see one"). While the nature of phonological change makes regular correspondences an obvious way to identify lexical cognates in data, such correspondences never have been (and should not be) a part of the theoretical definition of what a cognate is. Once this point is made clear, one can apply the same theoretical definition of cognacy to syntactic constructions and then, based on one's knowledge of how syntactic constructions change, search for the operational criteria that allow one to identify syntactic cognates, rather than mistakenly trying to apply operational criteria based on how form and meaning evolve in the process of diachronic lexical change. 


\subsection{Identification of Cognates}

We begin with the observation that cognates, whether lexical or syntactic, exist because it is possible for linguistic structures (both formal and semantic) to remain consistent between generations, and thus be inherited from source structures that were spoken many generations ago. Such inheritance need not involve change, but as more time passes, change becomes the rule. From this observation we derive our theoretical definition of the notion "cognate", from which any operational definition must follow: two linguistic items are cognate if they descend by direct inheritance from a common ancestor. Defined in this way, the question becomes how one can identify cognates, and especially, distinguish them from units that resemble cognates but are not. Identification of cognates is a methodological question, guided by operationally defined criteria: by what methods can one confidently assert that any two linguistic structures do, in fact, descend from a common ancestor? In particular, can one identify linguistic properties that are arguably unique to direct inheritance, and which can thus serve as circumstantial evidence for that status?

The first line of argument has to do with the plausible causes of similarity between linguistic structures. Before turning to syntax, we begin with the lexicon, asserting that lexical items from different languages that are sufficiently similar in both form and meaning are potential cognates. There is general agreement in the field that such similarity can only be due to one of four situations:

a) chance (the null hypothesis)

b) extra-linguistic factors (e.g. iconicity, in which onomatopoeic words resemble an external sound)

c) borrowing (received via contact)

d) cognacy (inherited from the same proto-language)

The weaker the degree of similarity, the more likely it is to be due to chance, and thus the more important it becomes to have methodological tools to overcome the likelihood that weak similarities are due to chance. All criteria that argue for cognacy derive their force from how specific sorts of similarity are identified, especially those which strengthen the argument against chance. For example, the more potential cognates one finds the less likely it is that each one, individually, could have arisen by chance. Likewise, when one can further specify regular patterns of similarity internal to the formal and/or semantic components of potential cognates, the statistical plausibility of chance diminishes. ${ }^{1}$

1 Although it is a logical possibility, we are aware of no examples of regularities in meaning change that have been used as primary arguments for lexical cognacy. The only role we have seen for semantic change is when scholars argue (apparently on an intuitive basis) about whether two given meanings are "similar enough" to be potential cognates. 
Once a similarity is too great to sustain the null hypothesis, then the task turns to identifying the type of common origin responsible for the similarity.

A non-historical explanation for similarity would be when potential lexical cognates have a common origin in that they have an iconic resemblance to something external to language, such as machine or animal noises. Such nonarbitrary forms are usually excluded from the set of cognates. Beyond these sorts of cases, it is generally accepted that for most of the lexicon the relation between sound and meaning is arbitrary. This means that when chance and factors like iconicity are discarded, the only account remaining is that the similarity must be due to a set of lexical items having their origin in a common source, whether transmitted by inheritance (cognates) or by contact (borrowings).

To begin with the simple case, if a lexical item is borrowed from an unrelated language, there is little likelihood that it will be similar enough in form to an inherited lexical item to be considered a potential cognate; this sort of borrowing merely reduces the number of potential cognates to be found. The more serious problem comes when lexical items are borrowed from a related language (cf. Bowern 2008: 199-200). In this situation, attested reflexes actually are descended from a common source, but via different pathways: inherited via a direct line of descent from the proto-language vs. inherited via a detour through another language/branch of the family. In a way, both of these would satisfy one component of the theoretical definition of cognates in that both trace back to the same proto-form; one might call these different subtypes "inherited cognates" and "borrowed cognates". On the one hand, this difference would not necessarily challenge our ability to reconstruct a shared proto-form, but it would call into question the pathways via which the shared proto-form arrived into each attested reflex. On the other hand, to the extent that sound changes may have differed along different pathways, it becomes possible to use such differences to distinguish "inherited cognates" from "borrowed cognates", which should allow a more reliable reconstruction of the sounds of the proto-form.

As such, the independent identification of the kinds of sound changes undergone by phonemes internal to potential cognates is a crucial tool both for arguing against chance and for distinguishing inherited from borrowed cognates. To give an example of the validity of statistically increased similarity, when comparing many potential lexical cognates, if one observes multiple cases in which a given sound (say /p/) in Language 1 corresponds to a specific sound (say /f/) in the same position in each potential cognate word in Language 2, such a structured similarity statistically decreases the plausibility of the null hypothesis. When every sound in each potential cognate in 
Language 1 corresponds to another specific sound in the potential cognate in Language 2, and when this holds over a large number of potential cognates, unless there is reason to suspect that there has been a massive relexification event (something akin to creole formation), even the most hardened skeptic is forced to concede a common origin, i.e., that the relevant words are indeed inherited cognates.

However, because of the widespread acceptance of the Regularity Hypothesis (Osthoff \& Brugman 1878), if such regular phonological correspondences are not found in any potential cognates, the Comparative Method obliges one to assume that the potential cognate did not descend via the same pathway, i.e., that the word with irregular correspondences must be similar due to chance or due to having been borrowed from a related language. Having identified the unexpected sound changes, one can then attempt to identify the donor language as one for which the non-conforming sound changes would have been expected. This method, the identification of regular phonological correspondences (what Walkden 2013: 101 calls the "Double Cognacy Condition") is the gold standard for establishing cognacy between lexical items.

Nevertheless, it is important to be clear that inheritance from a common ancestor is logically distinct from the creation of consistent internal correspondences in either form or meaning. That is, even in the domain of lexical comparison, the identification of correspondences is not the characteristic that defines a cognate; rather, it is the characteristic that effectively rules out alternative hypotheses, thus ending debate over whether two lexical items are cognate. In this sense, it is a logical error to require the equivalent of "regular correspondences" when seeking to identify cognates in other domains of language, such as syntax. The error is that this requirement entails setting aside the theoretical definition (cognates are linguistic structures inherited from a common source) and substituting for it a particular criterion (regular phonological correspondences/the Double Cognacy Condition) that is derived from a single domain of historical change (phonological change in the lexicon). Since such phonological correspondences are an outcome specific to processes of phonological change in lexical items, there is no reason to expect something identical in other domains of historical change, such as syntax.

This domain error seems to be at the root of the incongruous theoretical claim that cognates cannot be identified in syntax. Based on vast amounts of scholarship, it is widely agreed that the absence of regular phonological correspondences between suspiciously similar pairs of words is sufficient to conclude that they are not (inherited) cognates. Mutatis mutandis, the impossibility of identifying similar regular correspondences in potential syntactic cognates obliges the careful scholar to conclude that they, too, are not cognate. 
However, syntactic constructions arise and change via mechanisms unlike those that create regular phonological correspondences, so an exact analog to such correspondences will never be found in syntax. As such, it is almost tautological to conclude that it is impossible to identify cognates in syntax and therefore that one should reject claims by those who believe they have done so. When this false equivalency is laid bare, it becomes clear that the lack of such correspondences justifies only the much more limited conclusion that no potential syntactic cognates can qualify as fully lexical cognates.

Walkden (2013) makes a valiant effort to expand the validity from phonology and lexicon to syntax by reframing the requirement in more general terms as his "Double Cognacy Condition". This condition characterizes both the phonological correspondences inside lexical items and the lexical items themselves as "cognate", meaning each is independently inherited from a distinct protounit. Framed this way, it is the identification of the embedded "double cognate" phonemes inside each potential cognate lexical item that makes it possible to confirm them as cognates. Such "double cognates" are not found in syntax, he argues, because the combinations of units in syntactic constructions contain slots that are not fully determined, which means that they cannot be inherited by children in the same way as lexical items. Unlike words and sounds, which he claims are inherited directly from prior words and sounds, sentences are not inherited directly from prior sentences - rather, they are generated from abstract syntactic rules.

In Section 2 above we have discussed challenges to these empirical claims about the "direct" inheritance of lexical cognates. Here we add that, despite its more general phrasing, the Double Cognacy Condition is nothing more than a restatement of earlier attempts to import into the domain of syntactic change a method that was developed based on the process of regular phonological change in lexical items. It is time to let go of the bias that follows from trying to assess the likelihood of syntactic cognates using a method derived from phonological change in lexical cognates. Obviously one needs methods to assess the strength of potential syntactic cognates, but this should be done on the basis of our understanding of syntax and syntactic change, not other sorts of change.

In this regard, no matter how one interprets it theoretically, historical linguistics has an obligation to model the empirical fact that it is possible for syntactic constructions to remain consistent through multiple generations of speakers. Our methods must have a way to recognize and model such diachronic consistency before our theories can reasonably be expected to explain it. While it may be acceptable to claim that intergenerational transfer is different in the domains of phonology, lexicon, and syntax, it is not reasonable to 
insist that intergenerational consistency in phonology and lexicon constitute evidence for direct transfer whereas parallel consistency in syntax does not, as though such consistency in the domain of syntax might be some kind of historical accident. Historical syntacticians, too, would like a fully satisfying cognitive explanation for intergenerational consistency in all domains of language, but at the moment no explanation is in sight that is fully satisfying for any domain.

In the meantime, there is no reason to postpone the study of historical change in syntax while one awaits additional theoretical clarity. It is indeed possible to take what is already known about the facts of intergenerational continuity and discontinuity in syntactic patterns and use this knowledge to identify patterns that are both continuous and discontinuous. Given the theoretical definition of the term "cognate", it is self-evident that this is the appropriate label for constructions or syntactic patterns that do show intergenerational continuity.

As such, the task now is to elaborate a method by which to examine potential cognate constructions, a method that identifies types and degrees of similarity that could not plausibly arise by chance. Having eliminated the null hypothesis, one should also identify criteria that would aid in distinguishing between similarity due to contact (whether direct borrowing, calquing, or pattern replication) or due to language external factors (e.g., iconicity), as opposed to simple inheritance. Until we have elaborated such a method, it is premature to make any claims about the degree of confidence that we should place in these methods. This must be an empirical question, which will eventually need to be tested statistically (along the lines of the calculations made by Ringe 1992).

The first key to identifying cognates is to identify the point at which chance becomes an unreasonable explanation. Obviously, the strongest case against chance will be found when there is identity between constructions; this is the situation in which even the most skeptical scholars already accept that constructions are cognate (e.g., Lightfoot 2002a: 120; Walkden 2013: 98, 107). However, most of what is interesting about historical syntax involves the kinds of changes that take place, whether to entire constructions (in cases of reanalysis) or to the sub-components within constructions (cases of analogical extension, expansion of items that can occur in schematic slots, etc., cf. Section 4.2). As changes accrete to one or another of the attested reflexes of a proto-construction they will become increasingly different from one another, and as these differences become greater the intuitions of experts will reach less consensus about why the relevant reflexes are similar (i.e., whether they are cognate). For this reason, when potential cognate constructions are similar, 
but not identical, one needs methods to probe inside the larger constructions for specific properties that can be used as arguments for or against the null hypothesis.

From a Construction Grammar perspective (consistent with the synchronic approaches in, e.g., Goldberg 1995, 2006; Croft 2001; articulated diachronically in, e.g., Traugott \& Trousdale 2013; Barðdal \& Gildea 2015, inter alia), a construction is a combination of morphemes, more schematic "slots" (to be filled by lexical items selected from specific categories), and the syntactic relations between these elements. While it is not absolutely necessary for our argument here, it is the case that the meaning and/or distribution of a construction is not necessarily predictable by combining the meanings and/or distributions of its component subunits. That is, a construction as a whole can have its own meaning beyond the combinatory meanings of the elements within it. In this way, constructions resemble lexical items in being a combination of form (which contains consistent internal structure) and meaning (which may be derivable from the meanings of the subunit forms, but may also be arbitrary). What is crucial for identifying cognates is that the formal component of potential cognate constructions will contain multiple subunits that can be independently determined to be cognate: entire lexical items, bound morphology, constituent relations, etc. As the number of cognate subunits increases, the plausibility of the null hypothesis decreases. This same argument has been used successfully in frameworks that invoke theoretically less developed notions akin to construction, such as cognate "patterns" (Harris 1985, 2008; Harris \& Campbell 1995), cognate "verbal systems" (Gildea 1998), "cognate constructions" (in a pretheoretical sense; Gildea 2000), "cognate structures" (Kikusawa 2002, 2003).

As a programmatic suggestion, we list here a few of the most obvious candidates to anchor arguments against the null hypothesis when comparing potential syntactic cognates: ${ }^{2}$

a) The presence and location of cognate morphemes (whether free or bound)

b) The presence and location of schematic slots of specifiable types

c) Identity in linear order and/or constituency relations between cognate morphemes and/or schematic slots

2 See Seržant (2015: 125-130) for a somewhat overlapping methodological discussion, specifically what he labels morphological profile, lexical profile, syntactic profile, and semantic profile. While Seržant's methodological discussion does not characterize types of properties as we do here, most of these properties do appear in the detailed example of the independent partitive genitive that he provides later in that article. Of course, from our more constructional view, we do not compartmentalize such elements into distinct profiles, preferring to maintain a holistic view of all components internal to each construction being examined. 
d) Identity in other systematic relations amongst internal elements, e.g. argument structure patterns like case-marking, verb agreement, etc.

e) Either identical semantic values or a relation between the semantic values that is consistent with attested reanalyses in syntactic constructions (e.g. constructions containing a resultative participle $>$ perfective aspect $>$ past tense)

Unlike the phonemes that are sub-units in cognate lexical items, there are more varied types of subunits within syntactic constructions. Fixed morphemes are internally complex, being themselves full signs with structured form linked to meaning, capable of being independently identified as internal cognates within the larger cognate construction. Alongside fixed morphemes are schematic slots, some more and some less specified with regard to the sets of forms that can fill them. Even though such slots are less concrete than lexical items, they have both formal and semantic components that may be consistent between generations: formally, the locations of slots relative to each other and to fixed morphemes may themselves form fixed patterns or constituents; semantically, the list of elements (or more abstract properties that characterize such lists) could either be consistent or change over time. More abstract syntactic properties may also be consistent or subject to change, such as: phrase structure relations; overt coding properties of verbal argument structure like case-marking, verb agreement, and constituent order; covert properties of argument structure like control of coreference with reflexive morphemes or elided arguments in complex clauses; etc.

As we observe historical change in syntax, the subcomponents of syntactic structures have more autonomy than mere phonemes, able to change meaning in cases of reanalysis and to change form in cases of analogical extension. Despite these internal changes, the overall construction can retain a high degree of similarity with the source construction, similarity that cannot be explained as anything other than pattern consistency maintained between generations - that is, inheritance. Given the relative freedom to change what characterizes subcomponents of syntactic structures, most potential cognate constructions will not be identical. Examining the properties listed in $(\mathrm{a}-\mathrm{e})$ above gives us a way to consider both the similarities and the differences between them.

Critical to this perspective is that the existence of differences does not, in itself, invalidate the hypothesis of common origin - even if not identical, any degree of similarity too great to attribute to chance requires an account, whether due to contact, external factors (such as, in the domain of syntax, functionally-motivated typological patterns, as explicated in Seržant 2015 and 
Daniels 2015, 2020), direct inheritance from a proto-source, or some combination of the three. At the same time, even if one accepts the plausibility of shared origin one cannot simply dismiss the relevance of differences - ultimately, a satisfying reconstruction should identify both a source construction and a mechanism of change that could plausibly create each difference by changing elements of one (or each) sister construction after separation. In order to properly address the changes, we turn to the second major issue of this volume: how one can construct valid arguments to decide between competing hypotheses about directionality of change.

\subsection{Determining Directionality of Syntactic Change}

We begin our discussion of directionality in syntactic change by pointing out that in most cases, the kinds of syntactic change that are reconstructable are not global modifications of abstract phenomena like order of core constituents, but are rather the changes seen in more concrete, local constructions. For instance, Jeffers (1976) contrasts phonological reconstruction, where there is a basis for positing the expected evolution, and syntactic change, where he claims that there is no such basis, using the example of global word order: if two languages of the same family show different basic word-order (e.g., svo vs. sov), one cannot assess which was the original one or if they both come, in fact, from a different alternative.

However, once a specific set of cognate constructions has been identified, one faces a more limited problem, namely that of how to determine what changes might have created the differences, so that one can reconstruct the source construction from which these changes would have followed (for case studies on construction-specific word order change, cf. Claudi 1994; Gildea 200o; Kikusawa 2002; Barðdal et al. 2013). For example, given a set of cognate constructions, one can reconstruct one or another of the documented constructions as being identical to the source, with the others having changed to get to their attested forms, or one can reconstruct an unattested construction, such that all the documented constructions have undergone some change to arrive at their attested forms. In this way, it may be possible to narrow the problem of determining directionality to identifying what evidence allows for making a choice between specific competing hypotheses (called the 'pool of variants' in Vincent \& Roberts 1999; Roberts 2007: 362, 367-368). In this specific task, the following more concrete considerations may function as guidelines: a) Identification of the most plausible mechanisms of change, which may be recognized based on specific synchronic patterns in the cognate constructions 
b) Within these mechanisms of change, identifying preponderance of evidence for the direction of attested changes in parallel situations (this is especially valuable in cases of construction reanalysis)

c) In cases where the attested record does not provide any guidelines, a weaker metric is available in the form of more general principles that speak to the relative age of morphology found in constructions (Givón 2000: 120-121; Gildea 2002: 319-320)

d) The weakest of all the metrics is parsimony, in which the directionality is determined based on which proto-form would require fewer changes to arrive at the attested forms

We turn now to each of these considerations in turn.

\subsubsection{Mechanisms and Attested Direction of Change}

The standard set of mechanisms of change has been identified in multiple works as reanalysis, analogical extension, and borrowing (cf. Harris \& Campbell 1995; Hopper \& Traugott 2003; Gildea 1998; Barðdal \& Gildea 2015; and many other references contained in these sources). In very abbreviated terms, reanalysis (somewhat reconceptualized by Traugott \& Trousdale 2013: $35^{-} 37$ as neoanalysis) is change in the cognitive representation or conceptualization of a construction that does not lead to any immediate observable change in its formal properties. As such, reanalysis is a mechanism that leads to identical formal constructs with sometimes very different meanings, generally also with distinct functional and distributional profiles (cf. also Gildea 1998: 153-155); synchronically, it is not always clear to all analysts, especially those who focus on economy in structural representation, that immediate post-reanalysis constructions are different enough from their sources to merit distinct formal analyses.

In contrast, analogical extension (Hopper \& Traugott's 2003 analogy; Traugott \& Trousdale's 2013: $37-38$ analogization) is change in individual elements or patterns in the formal component of a construction, for example, a change in which a morpheme or collocational pattern from an independent construction in the language is "borrowed" into the innovating construction. Analogical extension is thus a mechanism that leads to irregular changes of individual morphemes or syntactic patterns, creating visible distinctions in individual cognate constructions. While analogical change also creates problems in the domain of phonology (especially morphophonological change), it is the prevalence of analogical change that makes syntactic cognates so different from lexical cognates, resulting in situations where constituent components differ between sister constructions that come from a common origin. Given this characterization of analogical extension, it is clear that the mechanism of 
borrowing is actually another manifestation of analogical extension, in which the independent construction that provides the source component is found in another language.

The relevance of these two mechanisms for determining directionality in reconstruction is particularly addressed in several works by Gildea (1998: $35^{-}$ 44; 2002: 316-320; 2008: 67-71), to which we refer readers for additional detail. When inspecting many examples of directionality in attested historical change, it is clear that reanalyses overwhelmingly proceed in a single direction, primarily by reducing complexity in innovative constructions. For example, there is a multitude of examples of biclausal constructions being reanalyzed as monoclausal, with erstwhile main clause verbs becoming auxiliaries and then inflections; in this process, subordinate inflections/derivations and other elements of subordinate clause grammar (e.g. argument structure) are introduced into main clauses. We have yet to identify any examples of the opposite directionality, i.e. monoclausal constructions being reanalyzed as biclausal, with main clause verbal inflections becoming auxiliaries and then complement-taking verbs, and some other component of the main clause then being reanalyzed as a subordinating morpheme, thereby introducing main clause grammatical patterns (like argument structure) into subordinate clauses. This claim is not theoretical, but empirical, and as such is subject to falsification in databases of attested change. Further, while this claim draws on much of the data brought to bear in the sometimes heated debates about unidirectionality in grammaticalization, we claim no theoretical significance to this observation, merely the instrumental significance that it facilitates identifying the direction of change in those specific instances where the mechanism is clearly reanalysis.

In contrast, attested examples of analogical extension appear to be relatively unconstrained in directionality; for example, specific morphemes from main clauses readily extend into subordinate clauses, specific morphemes from subordinate clauses can equally well extend into main clauses, and morphemes can also move about inside paradigms, which in turn may affect the morphological inventory of a given construction. However, to the extent that one is able to first identify the reanalysis that gave birth to a new construction, and to the extent that this enables one to identify the full set of components in the source construction, it is possible to distinguish which differences between erstwhile cognate constructions represent conservative vs. innovative component elements. Having identified which components are innovative, it is possible to discern where these components occur outside of the construction of interest. In most cases the "donor" construction is readily identifiable based on parallels to the function that the innovative component serves in the construction of interest. So even though the mechanism of analogical extension 
is not intrinsically directional, when the source construction and the donor construction can be identified on independent grounds, it becomes possible to identify the direction of change in specific cases of analogical extension.

With regard to borrowing, directionality is clear when the sources for specific morphemes can be traced to unrelated languages, or to related languages whose cognate morphology has undergone distinct phonological changes (cf. Daniels 2017: 303-304). However, when a borrowing takes the form of a calqued structure or a copied usage pattern (e.g. the "overuse" of a native passive construction when third person agents act on first or second person patients, a mechanism identified in Mithun 2006, 2012), the absence of borrowed morphology makes it more difficult to identify the effects of contact. Although contact effects of these kinds are inherently difficult to identify, to the extent that our purposes are limited to reconstructing individual constructions to a proto-language, and to the extent that copied usage patterns do, in fact, operate on constructions that were present in the proto-language, contactinduced change of this sort does not interfere with the identification of the proto-construction.

Despite the manifest differences between lexical/phonological and syntactic reconstruction, they share an important similarity: reconstructions are relatively straightforward when the time depth is shallow and they become increasingly difficult as the proto-language recedes farther into the past. In particular, it is easiest to reconstruct a case of recent reanalysis: (i) the source construction is often still attested, perhaps even in multiple languages; (ii) there have been enough changes in the reanalyzed reflexes to make it clear that the reanalysis has happened, that the modern reflexes are actually analytically distinct entities from their source; and (iii) there have not been so many individual changes in the reanalyzed reflexes as to obscure their shared inheritances from the source construction. As more time passes following the original reanalysis, (ii) becomes gradually more powerful and both (i) and (iii) less so; it is increasingly likely that the pre-reanalysed constructional source will no longer be attested and the accretion of individual analogical changes become themselves inherited patterns. Since the analogical changes are not inherently directional, it becomes difficult or impossible to argue confidently as to which formal elements are conservative (and hence reconstructable to the proto-construction) and which innovative.

For a concrete example of the process described above, in the Cariban family it is relatively straightforward to identify the sources of reanalyses that have relatively shallow time depth (summarized in Gildea 1998: 52-53), whereas not even all of the formal elements of the Proto-Cariban main clause construction are reconstructable, much less their sources (this is illustrated in Gildea 1998: 
Chapter 5 inter alia; for a more specific illustration, $\mathrm{cf}$. the reconstruction of number-marking on pp. 99-101).

When comparative information becomes less rich, or when it yields fewer cognate elements in particular cognate configurations, one needs other metrics to turn to that might help to separate older from more recent elements. In the next section, we review some of the metrics that have been proposed.

\subsubsection{The Role of General Principles in Diagnosing Directionality}

We open this section with the explicit caveat that the principles we list here are more heuristic than those in the previous section, following largely from the findings associated with grammaticalization studies. To the extent that they represent frequent outcomes of grammatical change, these are possible clues to the relative age of individual morphemes found in older constructions where the source constructions are no longer recoverable. In cases of internal reconstruction, where comparative evidence does not provide cognates outside of the attested construction, these principles may be the only criteria available to diagnose relative age.

Givón (2000: 120-121) offers the following general principles:

a) Phonetic Size: The smaller a morpheme is, the older it is

b) Semantic size: The more schematic (generic, grammaticalized, semantically opaque) the meaning of a morpheme is, the older it is

c) Distance from stem: Other things being equal, the closer a morpheme is to the stem/root of the word, the older it is

d) Morphophonemic irregularity: The more irregular or variable the allomorphs of a morpheme are, the older it is

While any of these individual properties could develop in more recent morphemes, when a morpheme is characterized by all four, it is hard to imagine a convincing argument that the reanalysis would be recent. Of course, very old morphemes can occur inside relatively recent constructions, so it is important not to confound the age of component morphemes with the age of the construction in which they occur.

In their discussion of directionality in Diachronic Construction Grammar, Traugott \& Trousdale (2013:112-124) identify three components of grammatical constructionalization as being consistently directional: increases in productivity and schematicity occur alongside decreases in compositionality (Barðdal \& Gildea 2015:15, 34, 37-41 have an independent discussion of these factors under the labels collocational expansion and increased schematization). Many constructions begin life with low type frequency, high coherence, and low schematicity. With the term low type frequency, we mean that few lexical items may occupy the open "slots" in the construction, with the term high coherence, we 
refer to the fact that the lexical fillers of the relevant slot are closely related semantically, and with the term low schematicity, we mean that the construction is used in a limited set of communicative contexts and its meaning/usage is more concrete, internally coherent, and perhaps componential. At the time of initial reanalysis, the meaning of a new schematic construction is already less compositional than that of the source. As a newer construction grows more productive, a greater number (and variety) of lexical items can occur in its open slots, leading to more complex lexical coherence among fillers of these slots and greater schematicity in usage. As such, increased productivity then drives a still less-concrete, less-componential constructional meaning.

As an illustration of the development described above, early on in the evolution of the English way-construction, only the verb go appeared; by 1700 the number had expanded to 16 motion verbs, by 1875 to 38 motion verbs (with increasingly convoluted path or manner semantics), and by now the modern construction seems to be a productive venue for non-motion verbs to gain (sometimes metaphorical) motion semantics (Israel 1996). Similarly, in the early stages of the English Progressive construction, the verb slot was limited to activity verbs expressing events that took place in a stereotypical location; as the construction developed, both of these restrictions gradually eased, leading to the highly productive Progressive Construction attested today (Bybee, Perkins \& Pagliuca 1994: 136; Heine, Claudi \& Hünnemeyer 1991: 214-215). To the extent that cognate constructions in different languages differ in terms of semantic compositionality, productivity, and schematicity, this metric would predict that the less productive and schematic versions of the construction would be younger, that is, closer to the original reanalysis.

The final directionality metric that we discuss here is parsimony, which would lead us to reconstruct a source construction or grammatical pattern by selecting the hypothesized proto-form that requires the fewest changes in order to arrive at the attested forms. On the one hand, this metric requires a priori a reasonably solid classification of the languages in question, so as to plot the number of changes accurately through the branches. On the other hand, it is important to bear in mind that both cognate morphemes and cognate grammatical patterns are internal components of entire cognate constructions. When the goal is to reconstruct a specific grammatical morpheme, as it often is in grammaticalization studies, or a specific typological pattern, it is possible to lose sight of the constructional context and consider only the pattern in question, which in turn may lead to a claim of parsimony that is divorced from the larger constructional context.

For example, in a simple application of parsimony, when a construction is found only in one sub-branch, with some competing construction serving the 
same function in the rest of the family, it is more economical to reconstruct this as an innovation at the level of that one sub-branch rather than to the proto-language. This reflects parsimony in that the more widespread construction would be inherited, and as such would achieve its broader distribution via fewer innovations. This conclusion would further entail that the construction with more restricted distribution would be a recent innovation, limited to a single branch. In addition to providing an economical account of these creative innovations, such a reconstruction also offers an economical approach to the negative side of these innovations: the older construction has been lost in only one branch and the innovative construction never existed in the rest of the family, and so there is no parsimony cost in its loss.

However, because innovative constructions come from source constructions with source morphology that generally occurs also externally to the source construction, the simple hypothesis does make the implicit claim that the innovative construction is the result of a relatively recent reanalysis compared to its more widespread competitor. This claim can be tested by identifying cognates to the component morphology that could have combined into a plausible source construction; ideally this cognate morphology (and even the source construction) would be found throughout the family, but certainly it should be seen in the branch where the innovative construction is attested. If source morphology is not attested, then one must seriously consider the alternative hypothesis, which is that the minority construction is actually an archaism that reconstructs to the proto-language, but has been lost in the rest of the genetic unit. Gildea (2002: 320 ) frames this as a general principle:

Identifiable Source Forms: Morphology that has no "cognates" elsewhere in the grammar to serve as possible source forms for reanalysis or extension, or that was not plausibly borrowed into the language from an identifiable source in another language, is more likely to be old.

This principle follows from considerations of parsimony, in recognition of the costs of losing cognate source material in a relatively shallow time period. One more difference between syntactic constructions and lexical items is that constructions generally contain multiple morphemes and sub-constructions, most of which began outside of the construction in question; prior to the reanalysis that created the innovative construction, a given sequence of morphemes and slots could have been simply one collocation among others. At the time of initial reanalysis, the source construction with all of its component morphemes should continue to exist alongside the innovative construction. As time passes, an innovative construction and its source construction will drift apart, each 
changing independently and each also independently available to be inherited by subsequent daughter languages.

The loss of the source construction, as well as each independent loss of a lexical or morphological source, must be counted as separate changes; if all traces of the source construction have been lost, this effectively neutralizes the simple argument from parsimony. In the absence of a clear argument from economy, the question shifts to one of how plausible each timeline appears. With a greater time depth, simple lexical replacement makes it increasingly likely that the source lexical items and other morphology would have been replaced by innovative forms, and indeed it is not unusual for an older construction to contain morphology that has no obvious external source forms. However, if one posits that a construction with no external cognate morphology is a relatively recent innovation, then not just the source construction, but all its component source forms must have been lost in every branch of the family; at least the most local of these losses must have taken place in the time period since the initial reanalysis in the one branch where the innovation is found. ${ }^{3}$ This invites one to seek source components for the more widespread construction(s) in the other branches of the family; if those are readily identifiable, this would serve to effectively reverse the argument from parsimony, making it more plausible that the widespread construction is the innovation and the construction with more restricted distribution is conservative.

Following this principle, Gildea (1998: 51) uses the lack of identifiable source forms for personal prefixes, TAM suffixes, and the personal number suffix as evidence that a given construction containing those morphemes (his "Set I verbal system") reconstructs back to Proto-Cariban. Similarly, partly on the basis of the absence of source forms, Gildea (2002:322-323) argues that the A/Sa subset of the personal prefixes in Proto-Tupi-Guarani represents an older component of the hierarchical agreement system, in particular prior to the addition of the $\mathrm{O} /$ So prefixes, for which sources are still readily identifiable. Pacchiarotti (this volume) provides another nice exposition of this situation in her reconstruction of the source of the case marker for the subject possessor in the Viceitic (Chibchan) alienable possession construction.

With these principles, once we are able to identify cognates, we are well equipped with knowledge about syntactic change that allows for positing a reconstructed construction, pattern, or feature from which the grammars of

3 To be fair, given the inevitable limitations of grammatical descriptions, and in particular the preliminary state of description for some languages (and language families) of the world, it is a logical possibility that source forms may still exist, but have simply not yet been described. 
the descendant languages are more likely to be explained. These principles are broadly compatible with Givón's (1971: 413) well-known remark that "today's morphology is yesterday's syntax", and indeed these principles owe much to the decades of work in grammaticalization, which has aided us in recognizing lexical cognates by "undoing" the processes that have led to the grammaticalization of elements like clitics, auxiliary verbs, bound morphemes, etc., and which also provide many of the examples of specific constructional changes. Despite the historical disconnect between the intellectual communities dedicated, on the one hand, to the comparative method and, on the other, to grammaticalization studies, we suggest that the principles as articulated here are compatible with both approaches.

This concludes our theoretical arguments, and the methodological principles that follow from them. We turn now to the contributions in the remainder of this volume.

The final step of the Comparative Method is to propose an original state of affairs that may account for the outcomes found in the attested languages. With this in mind, Eythórsson \& Barðdal (2016: 87) point out that many articles and books dealing with syntactic reconstruction do not actually carry out a reconstruction. Rather, they draw a scenario that allows us to understand the development from the proto-language to the attested descendant languages; in that scenario a reconstruction of the original stage may be implicit, but most times it is not presented in detail and the exact status of the reconstruction is not discussed. The eight chapters that appear in this volume all offer explicit reconstruction of syntax. Since all were written before this introduction was written, each represents an independent solution to the problems discussed in Section 4. Four of the chapters deal with the issue of how to identify cognates: Gildea \& Castro Alves, Kikusawa, Luraghi and Barðdal \& Eythórsson. The remaining four chapters are concerned with directionality in syntactic change: Pacchiarotti, Lavidas \& Kulikov, Pat-El, and Luján \& López Chala. We offer a brief summary of each of these contributions below.

Gildea \& Castro Alves focus their efforts on reconstructing a specific grammatical pattern that is typologically rare, in which nominative case marking of pronouns co-occurs with absolutive indexation of main verbs. This pattern was originally attested in only the Jê and Cariban language families, both spoken in the Amazonian region of South America. Gildea \& Castro Alves do not attempt to reconstruct these patterns in the abstract, but rather they identify 
and reconstruct the subordinate source constructions that contain absolutive verbal indexation alongside ergative case marking of a free nominal A. They then identify two kinds of biclausal source constructions that led to the loss of the ergative case-marked A. In the first type, the S/A of the matrix clause is coreferential with the $\mathrm{A}$ of the subordinate clause, leading to a complex clause in which the A of the subordinate clause simply does not occur. In the second type, the source construction does not contain such coreference conditions, thus, after reanalysis, the innovative construction contains an ergative A. In subsequent constructional changes, two distinctive patterns emerge. In Timbira, the ergative A is conserved in the past tense, but is replaced by an unmarked topic pronoun/noun in the nonpast. In the Suyá future and negative, the ergative is conserved in pronoun subjects, but for nominal subjects, the ergative marking is lost. None of these represent deep reconstructions: the lexical and morphological cognates within the innovative constructions provide a clear roadmap to reconstructing the source constructions, from which the directionality of additional changes can be identified.

Kikusawa introduces a methodology for carrying out syntactic reconstruction for languages for which no written records exist. In such cases, the comparanda must be extracted from modern languages for which genetic relations have already been established. Kikusawa compares the alignment system of five Austronesian languages which between them show high disparity of alignment patterns. As a first step, abstract clause structures are described and classified on the basis of transitivity and case marking, providing a descriptive representation from which patterns belonging to typologically different languages may be compared. Each clause structure is also marked for the position in which the remnants of earlier genitive pronouns are found; these are traditionally analyzed as ergative markers, having marked the A of transitive clauses. Through this step, cognate clause structures are established. The second step involves comparing and analyzing the different positions found with the genitive across the five daughter languages. This reveals that the genitive is not limited in distribution to transitive clauses, but is also found in both monadic and dyadic intransitives, and also in languages with a synchronic accusative system. A further comparison uncovers an earlier merger of the genitive and the nominative pronominal sets. The third step in this process is to identify the directionality of the relevant change. To this end, further scrutiny of the data reveals that the morphological merger of the genitive/nominative appears to be functionally motivated by a change in word order from verbsubject to subject-verb clause structure. On this basis, Kikusawa reconstructs Proto-Malayo-Polynesian as an ergative system, from which she tracks its development into the different types of alignment systems found in the five daughters under discussion. 
Luraghi analyses two different external possessor constructions across the early Indo-European daughter languages, i.e. the dative external possessive construction and the double case construction, both denoting inalienable possession. The two constructions are unevenly distributed across the daughter languages, with the double case construction found only in Homeric Greek, Hittite and Armenian. However, the syntactic and semantic properties documented for the double case construction do not converge in these three languages, thus suggesting that the relevant constructions are innovations in all three branches. In contrast, the dative external possessive construction is found in Greek, Latin, Germanic, Baltic, Slavic, Hittite and Vedic with similar syntactic and semantic properties. The evidence from Hittite is ambiguous, and while it is scanty for Vedic, it still suggests a Proto-Indo-European origin. Luraghi analyses both the syntactic and the semantic properties of the relevant constructions, and only in instances where the syntactic and semantic properties are a match across the daughter languages does she argue that they have a shared origin.

Barðdal \& Eythórsson propose a research program for how to identify cognates in syntax, in particular within the realm of argument structure. They base their program on Watkins' (1995) proposal that it may be possible to reconstruct larger units of grammar through identifying morphological flags of larger constructions. This - as they point out - is no insignificant part of grammar: the whole of morphosyntax. In more detail, Barddal \& Eythórsson propound that cognates in argument structure constructions may be identified through a) cognate lexical verbs, b) cognate case frames, c) cognate predicate structure and d) cognate case morphology. They then suggest supplementing Watkins' proposal with one further analytical step, namely through e) identifying cognate argument structure constructions with the aid of noncognate, but synonymous, lexical predicates. The rationale behind this addition to the program lies in facts of lexical replacement in general and known patterns of changes in argument structure in particular. This program allows for the identification of cognate argument structure constructions across a deeper time span than corresponding reconstructions based only on cognate lexical verbs.

Pacchiarotti begins with a typologically unusual case-marking pattern in the Costa Rican languages Bribri and Cabécar (from the Viceitic branch of Chibchan), in which the transitive subject is marked with one ergative marker in most constructions, but with a different ergative marker, a mysterious wã in the Perfect (a.k.a "Anterior") construction. She identifies the immediate source of the Perfect construction as a resultative participle in a possessive construction (a source well-known from European languages). In the source possessive predicate construction, the possessor is marked by wã. Next, Pacchiarotti attempts to find a deeper source for this Possessor marker wã. Given that there 
is no readily available synchronic source in Bribri or Cabécar, she searches for cognates in Possessive Predicate constructions throughout the Isthmic branch (to which Viceitic belongs), but finds only unconvincing prospects. According to the principle of parsimony, one might conclude that $w \tilde{a}$ was an innovation in Proto-Viceitic. However, this conclusion clashes with the fact that there is no synchronically available source in either Viceitic or Isthmic for this alleged 'new' piece of grammar. By expanding her search beyond the Isthmic branch, Pacchiarotti identifies other possible cognates, some quite distant. These ultimately allow her to reconstruct a Proto-Chibchan possessive predicate construction in which the source of the Viceitic possessor marker wã reconstructs back to a Proto-Chibchan word meaning 'thing'.

Lavidas \& Kulikov's contribution is focused on the directionality of changes in the domains of tense-aspect and transitivity-voice in the history of Vedic and Ancient Greek, a topic falling out from their reconstruction of the linguistic system of Proto-Indo-European, manifested as "split causativity" in the daughters. Lavidas \& Kulikov document a correlation between verbal formations of the present system being used transitively or causatively, on the one hand, and being used intransitively, on the other. The evidence for their reconstruction is found through relics in Vedic and innovations in Ancient Greek. The Vedic relics consist of active perfects that show up as intransitives, thus being functionally middles, while the innovations in Ancient Greek are manifested through the rise of new markers of transitivity oppositions. These new oppositions consist of the common distinctions between active vs. passive, on the one hand, and causative vs. anticausative, on the other. Thus, changes in voice are parallel with another development in the history of Greek, namely the separation of tense and aspect. Active morphology thus becomes associated with transitive alternations rather than aspectual properties. The development that Lavidas \& Kulikov outline serves as evidence for the directionality of the historical changes that have taken place in the linguistic system of Koine Greek, triggered by the original oppositions of the relevant domains of tenseaspect and transitivity-voice in the proto-language.

Pat-El focuses on the development of adverbial subordination across several Semitic languages; subordination patterns which are parallel in many respects, except that the subordinators are not lexically cognate. Pat-El discusses two different potential scenarios for reconstruction: a) one assuming a proto-structure for these subordination patterns with lexical replacement being responsible for lack of cognates, or b) parallel development motivated by a certain type of nominally headed relative clauses. Case morphology of nouns in nominally headed relatives is typically impoverished due to the status of such nouns as proclitics, leading to a reanalysis of nominal heads with 
spatial, temporal and causal meaning as adverbial subordinators. Pat-El argues for the second reconstructional scenario outlined above, proposing that a certain type of relative clause may be responsible for the parallel development in each of the daughter languages. On this analysis it is assumed that parallel development has taken place multiple times and that the impetus for the development has been carried down to the daughters, in fact still being a part of the synchronic grammar of the relevant daughter languages where this adverbial subordination pattern exists. While emphasizing that the relevant structures across the daughters are most likely the result of independent parallel development, Pat-El also highlights the fact that parallel developments are set in motion by shared structures which create the type of coercion needed for analogous evolutionary paths to emerge.

Luján \& López Chala focus on the fate of the desinences based on PIE ${ }^{*}-b^{h_{i}}$ in the ancient Indo-European languages in order to reconstruct the history of this morpheme and the semantic path that it has followed since its PIE origins. Endings continuing PIE ${ }^{*}-b^{h} i$ occur in several branches of the Indo-European family, both in the nominal and in the pronominal declension. They display a whole array of different semantic roles that range from their use as prototypical Recipients with pronouns to the expression of Instrument, Comitative, Agent, Manner or Place with nouns. The most common use of ${ }^{*}-b^{h} i$-endings across languages is as an Instrumental marker and, therefore, ${ }^{*}-b^{h} i$ has traditionally been reconstructed as the athematic instrumental plural ending of PIE. However, traditional reconstructions were "static" and did not pay explicit attention to the semantic paths of change followed by the ending and to the actual occurrence of different meanings that were not easy to reconcile. In their "dynamic" approach Luján \& López Chala argue that the directionality of the change can be reconstructed on the basis of what we currently know about the historical tendencies of change of the markers of semantic roles. This allows for an integrated account of the history of the desinence and the reconstruction of its original Comitative value, which, in turn, must have been the result of a grammaticalization process of a postposition with local meaning ('by, next to').

\section{Acknowledgements}

For comments and discussion, we thank Don Daniels, Andrey Nikulin, Sara Pacchiarotti, Roland Pooth, and Ilja Seržant. We are also most grateful to the organizers of ICHL-2O for hosting Barðdal and Gildea's original workshop on the topic of reconstructing syntax in Osaka (2011), to Thomas Smitherman 
for his early efforts on the editorial team, to Brill's assistant editors, Maarten Frieswijk and Elisa Perotti, for their hard work and dedication, as well as to Angela Terrill for her excellent work on copyediting the entire volume during the final stages of this project. We also thank the external reviewers for their role in increasing the quality of the individual articles in this volume and, last but not least, the contributors themselves, as without them, this volume would not have seen the light of day. Of course, all errors are solely our responsibility. This research was supported with several generous research grants: Jóhanna Barðdal's work was funded by the Norwegian Research Council (NonCanCase, grant nr. 205007), during the early phases of this project, and by the European Research Council (EvALISA, grant nr. 313461), during the final stages of this book project. Eugenio R. Luján's work was funded by the Spanish Ministry of Economy and Competitiveness (grant nr. FFI2015-63981-C3-2), and Spike Gildea's work was funded in part by grants from the National Science Foundation (BCS-0936684, Sahaptian and the Evolution of Hierarchical Systems with Joana Jansen and BCS-1500714, Documentation of Yawarana [yar] with Natalia Cáceres \& Marie-Claude Mattei Muller), as well as by a European Science Foundation/EuroCORES: EuroBABEL Collaborative Research Project, Referential Hierarchies in Morphosyntax (RHIM).

\section{References}

Adger, David. 2003. Core Syntax: A Minimalist Approach. Oxford: Oxford University Press.

Barðdal, Jóhanna. 2013. Construction-Based Historical-Comparative Reconstruction. The Oxford Handbook of Construction Grammar, ed. by Graeme Trousdale \& Thomas Hoffmann, 438-457. Oxford: Oxford University Press.

Barðdal, Jóhanna. 2014. Syntax and Syntactic Reconstruction. The Routledge Handbook of Historical Linguistics, ed. by Claire Bowern \& Bethwyn Evans, 343-373. London: Routledge.

Barðdal, Jóhanna, Valgerður Bjarnadóttir, Serena Danesi, Tonya Kim Dewey, Thórhallur Eythórsson, Chiara Fedriani \& Thomas Smitherman. 2013. The Story of 'Woe'.Journal of Indo-European Studies 41(3-4): 321-377.

Barðdal, Jóhanna \& Thórhallur Eythórsson. 2012a. Reconstructing Syntax: Construction Grammar and the Comparative Method. Sign-Based Construction Grammar, ed. by Hans C. Boas \& Ivan A. Sag, 257-308. Stanford: CSLI Publications.

Barðdal, Jóhanna \& Thórhallur Eythórsson. 2012b. "Hungering and Lusting for Women and Fleshly Delicacies": Reconstructing Grammatical Relations for Proto-Germanic. Transactions of the Philological Society $110(3): 363-393$. 
Barðdal, Jóhanna \& Spike Gildea. 2015. Diachronic Construction Grammar: Epistemological Context, Basic Assumptions and Historical Implications. Diachronic Construction Grammar, ed. by Jóhanna Barðdal, Elena Smirnova, Lotte Sommerer \& Spike Gildea, 1-50. Amsterdam:John Benjamins.

Barðdal, Jóhanna \& Thomas Smitherman. 2013. The Quest for Cognates: A Reconstruction of Oblique Subject Constructions in Proto-Indo-European. Language Dynamics and Change 3(1): 28-67.

Bauer, Brigitte. 200o. Archaic Syntax in Indo-European: The Spread of Transitivity in Latin and French. Berlin: Mouton de Gruyter.

Beekes, Robert S. P. 2011. Comparative Indo-European Linguistics: An Introduction (2nd revised ed. by Michiel de Vaan). Amsterdam: John Benjamins.

Boas, Hans C. 2003. A Constructional Approach to Resultatives. Stanford: CSLI Publications.

Bowern, Claire. 2008. Syntactic Change and Syntactic Borrowing in Generative Grammar. Principles of Syntactic Reconstruction, ed. by Gisela Ferraresi \& Maria Goldbach, 187-216. Amsterdam: John Benjamins.

Bowern, Claire. 2017. General and Methodological Issues. Handbook of Comparative and Historical Indo-European Linguistics, vol. 1, ed. by Jared Klein, Brian Joseph, Matthias Fritz \& Mark Wenthe, 1-7. Berlin: Walter de Gruyter.

Bybee, Joan, Revere Perkins, \& William Pagliuca. 1994. The Evolution of Grammar: Tense, Aspect, and Modality in the Languages of the World. Chicago: University of Chicago Press.

Campbell, Lyle. 1986. Theories of Syntactic Change and Finnish Historical Syntax. Journal of the Atlantic Provinces Linguistic Association 8: 72-93.

Campbell, Lyle. 1988. Review of Language in the Americas, by Joseph H. Greenberg, 1987. Language 64: 591-615.

Campbell, Lyle. 1998. Historical Linguistics: An Introduction. Edinburgh: Edinburgh University Press.

Campbell, Lyle. 2003. How to Show Languages Are Related: Methods for Distant Genetic Relationship. The Handbook of Historical Linguistics, ed. by Brian D. Joseph \& Richard D. Janda, 262-282. Oxford: Blackwell.

Campbell, Lyle \& William Poser. 2008. Language Classification: History and Method. Cambridge: Cambridge University Press.

Clackson, James. 2007. Indo-European Linguistics. Cambridge: Cambridge University Press.

Claudi, Ulrike. 1994. Word Order Change as Category Change. Perspectives on Grammaticalization, ed. by William Pagliuca, 191-231. Amsterdam: John Benjamins.

Croft, Willam. 2001. Radical Construction Grammar: Syntactic Theory in Typological Perspective. Oxford: Oxford University Press. 
Danesi, Serena, Cynthia A. Johnson \& Jóhanna Barðdal. 2017. Between the Historical Languages and the Reconstructed Language: An Alternative Approach to the Gerundive + "Dative of Agent" Construction in Indo-European. Indogermanische Forschungen 122: 143-188.

Daniels, Don. 2015. A Reconstruction of Proto-Sogeram: Phonology, Lexicon, and Morphosyntax. University of California, Santa Barbara, Ph.D. dissertation.

Daniels, Don. 2017. A Method for Mitigating the Problem of Borrowing in Syntactic Reconstruction. Studies in Language 41(3): 577-614.

Daniels, Don. 2020. Grammatical Reconstruction: The Sogeram Languages of New Guinea. Mouton De Gruyter.

Delbrück, Berthold. 1878. Die altindische Wortfolge aus dem Çatapathabrähmana dargestellt (Syntaktische Forschungen III). Halle: Verlag des Waisenhauses.

Delbrück, Berthold. 1893-1900: Vergleichende Syntax der indogermanischen Sprachen I-III. Strassburg: Trübner.

Delbrück, Berthold. 1907. Synkretismus. Ein Beitrag zur germanischen Kasuslehre. Strassburg: Trübner.

Dixon, R. M. W. 1997. The Rise and Fall of Languages. Cambridge: Cambridge University Press.

Drinka, Bridget. 1999. Alignment in Early Proto-Indo-European. Language Change and Typological Variation: In Honor of Winfred P. Lehmann on the Occasion of his 83 rd Birthday, Vol II, ed. by C. F. Justus \& E. C. Polomé, 464-50o. Washington, DC: Institute for the study of Man.

Dunn, Michael, Tonya Kim Dewey, Carlee Arnett, Thórhallur Eythórsson \& Jóhanna Barðdal. 2017. Dative Sickness: A Phylogenetic Analysis of Argument Structure Evolution in Germanic. Language 93(1): e1-e22.

Dybo, Anna V., \& George S. Starostin. 2008. In Defense of the Comparative Method, or the End of the Vovin Controversy. Aspects of Comparative Linguistics 3 (Moscow: Russian State University for the Humanities), 119-258.

Eythórsson, Thórhallur \& Jóhanna Barðdal. 2011. Die Konstruktionsgrammatik und die komparative Methode. Indogermanistik und Linguistik im Dialog: Akten der XIII. Fachtagung der Indogermanischen Gesellschaft vom 21. bis 27. September 2008 in Salzburg, ed. by Thomas Krisch \& Thomas Lindner, 148-156. Wiesbaden: Reichert.

Eythórsson, Thórhallur \& Jóhanna Barðdal. 2016. Syntactic Reconstruction in Indo-European: State of the Art. Veleia 33: 83-102.

Ferraresi, Gisella \& Maria Goldbach (eds.). 20o8. Principles of Syntactic Reconstruction. Amsterdam: John Benjamins.

Fillmore, Charles J., Paul Kay \& Mary Catherine O'Connor. 1988. Regularity and Idiomaticity in Grammatical Constructions: The Case of Let Alone. Language 64: 501-538.

Fortson, Benjamin W. IV. 2004. Indo-European Language and Culture: An Introduction. Oxford: Blackwell. 
Fox, Anthony. 1995. Linguistic Reconstruction: An Introduction to Theory and Method. Oxford: Oxford University Press.

Fried, Mirjam \& Jan-Ola Östman. 2005. Construction Grammar and Spoken Language: The Case of Pragmatic Particles. Journal of Pragmatics 37(11): 1752-1778.

Friedrich, Paul. 1975. Proto-Indo-European Syntax. Washington: Institute for the Study of Man.

Gamkrelidze, Thomas V. \& Vjaceslav V. Ivanov. 1995. Indo-European and the Indo-Europeans: A Reconstruction and Historical Analysis of a Proto-Language and Proto-Culture I-II [Translated by Johanna Nichols]. Berlin: De Gruyter Mouton.

Garrett, Andrew. 1990. The Syntax of Anatolian Pronominal Clitics. Harvard University $\mathrm{PhD}$ dissertation.

Gildea, Spike. 1992. Comparative Cariban Morphosyntax: On the Genesis of Ergativity in Independent Clauses, University of Oregon PhD dissertation.

Gildea, Spike. 1998. On Reconstructing Grammar: Comparative Cariban Morphosyntax. Oxford: Oxford University Press.

Gildea, Spike. 20oo. On the Genesis of the Verb Phrase in Cariban Languages. Reconstructing Grammar: Comparative Linguistics and Grammaticalization, ed. by Spike Gildea, 65-106, Amsterdam: John Benjamins.

Gildea, Spike. 2002. Pre-Proto-Tupí-Guaraní Main Clause Person-Marking. Línguas Indígenas Brasileiras. Fonologia, Gramática e História. Atas do I Encontro Internacional do GTLI da ANPOLL, Vol I, ed. by Ana Suelly Cabral \& Aryon Rodrigues, 315-326. Belem: Editoria Universitária U.F.P.A.

Gildea, Spike. 2008. Explaining Similarities between Main Clauses and Nominalized Clauses. La structure des langues amazoniennes, ed. by Ana Carla Bruno, Frantomé Pacheco, Francesc Queixalos, \& Leo Wetzels. Amérindia 32: 57-75.

Givón, Talmy. 1971. Historical Syntax and Synchronic Morphology: An Archaeologist's Field Trip. Chicago Linguistic Society 7: 394-415.

Givón, Talmy. 200o. Internal Reconstruction: As Method, as Theory. Reconstructing Grammar: Comparative Linguistics and Grammaticalization Theory, ed. by Spike Gildea, 107-159. Amsterdam: John Benjamins.

Goldberg, Adele E. 1995. Constructions: A Construction Grammar Approach to Argument Structure. Chicago: University of Chicago Press.

Goldberg, Adele E. 20o6. Constructions at Work: The Nature of Generalization in Language. Oxford: Oxford University Press.

Greenberg, Joseph. 1957. Essays in Linguistics. Chicago: University of Chicago Press.

Greenberg, Joseph H. 1966. Some Universals of Grammar with Particular Reference to the Order of Meaningful Elements. Universals of Language, 2nd ed., ed. by Joseph H. Greenberg, 73-113. Cambridge, Mass: MIT Press.

Greenberg, Joseph. 1987. Language in the Americas. Stanford: Stanford University Press. Greenberg, Joseph. 1989. Classification of American Indian Languages: A Reply to Campbell. Language 65: 107-114. 
Hale, Mark. 1987. Notes on Wackernagel's Law in the Language of the Rigveda. Studies in Memory of Warren Cowgill, ed. by Calvert Watkins, 38-50. Berlin: De Gruyter.

Hale, Mark. 2007: Historical Linguistics: Theory and Method, Oxford: Blackwell.

Harris, Alice C. 1985. Diachronic Syntax: The Kartvelian Case. New York: Academic Press. Harris, Alice C. 2008. Reconstruction in Syntax: Reconstruction of Patterns. Principles of Syntactic Reconstruction, ed. by Gisella Ferraresi \& Maria Goldbach, 73-95. Amsterdam: John Benjamins.

Harris, Alice C. \& Lyle Campbell. 1995. Historical Syntax in Cross-Linguistic Perspective. Cambridge: Cambridge University Press.

Harrison, S. P. 2003. On the Limits of the Comparative Method. The Handbook of Historical Linguistics, ed. by Brian D. Joseph \& Richard D. Janda, 213-243. Oxford: Blackwell.

Havers, Wilhelm. 1911. Untersuchungen zur Kasussyntax der idg. Sprachen. Strassburg: Trübner.

Heine, Bernd, Ulrike Claudi, \& Friederike Hünnemayer. 1991. Grammaticalization: A Conceptual Framework. Chicago: University of Chicago Press.

Heine, Bernd \& Tania Kuteva. 2004. World Lexicon of Grammaticalization. Cambridge: Cambridge University Press.

Hock, Hans H. 20oo. Genre, Discourse and Syntax in Early Indo-European, With Emphasis on Sanskrit. TextualParameters in OlderLanguages, ed. by Susan C. Herring, Pieter van Reenen \& Lene Schøsler, 163-195. Amsterdam: John Benjamins.

Hoenigswald, H. M. 1978. The Annus Mirabilis 1876 and Posterity. Transactions of the Philological Society 76: 17-35.

Hopper, Paul \& Elizabeth Closs Traugott. 2003. Grammaticalization. 2nd ed. Cambridge: Cambridge University Press.

Israel, Michael. 1996. The Way Constructions Grow. Conceptual Structure, Discourse and Language, ed. by Adele E. Goldberg, 217-230. Stanford: CSLI.

Jackendoff, Ray. 1997. Twistin' the Night Away. Language 73: 534-559.

Jeffers, Robert J. 1976. Syntactic Change and Syntactic Reconstruction. Current Progress in Historical Linguistics: Proceedings of the Second International Conference on Historical Linguistics, Tucson, Arizona 12-16 January 1976, ed. by William M. Christie, 1-16. Amsterdam: North Holland.

Johnson, Cynthia A., Peter Alexander Kerkhof, Leonid Kulikov, Esther Le Mair \& Jóhanna Barðdal. 2019. Argument Structure, Conceptual Metaphor and Semantic Change: How to Succeed in Indo-European without Really Trying. Diachronica 36(4): 463-508.

Jolly, Julius. 1872. Ein Kapitel vergleichender Syntax: Der Conjunktiv und Optativ und die Nebensätze im Zend und Altpersischen. Munich: Ackermann.

Justus, Carol F. 1993. Dislocated Imperatives in the Indo-European Prayer. Word 44: $273^{-294}$ 
Justus, Carol F. 20oo. Word Order and the First Person Imperative. Stability, Variation and Change of Word-Order Patterns over Time, ed. by Rosanna Sornicola, Eric Poppe \& Ariel Shisha-Halevy, 165-184. Amsterdam: John Benjamins.

Keydana, Götz. 2018. The Syntax of Proto-Indo-European. Handbook of Comparative and Historical Indo-European Linguistics, vol. 3, ed. by Jared Klein, Brian Joseph, Matthias Fritz \& Mark Wenthe, 2195-2228. Berlin: Walter de Gruyter.

Kikusawa, Ritsuko. 2002. Proto Central Pacific Ergativity: Its Reconstruction and Development in the Fijian, Rotuman and Polynesian Languages. Canberra: Pacific Linguistics.

Kikusawa, Ritsuko. 2003. The Development of Some Indonesian Pronominal Systems Historical Linguistics 2001: Selected Papers from the 15th International Conference on Historical Linguistics, Melbourne, 13-17 August 2001, ed. by Barry J. Blake, Kate Burridge \& Jo Taylor, 237-268. Amsterdam: John Benjamins.

Klein, Jared S. 2010. Review of Principles of Reconstruction, ed. by Gisela Ferraresi \& Maria Goldbach (2008), Language 86: 720-726.

Klimov, G. A. 1977. Tipologija jasykov aktivnogo stroja [The Typology of Active Languages]. Moscow: Nauka.

Krasukhin, Constantin G. 2017. Methods in Reconstruction. Handbook of Comparative and Historical Indo-European Linguistics, vol. 1, ed. by Jared Klein, Brian Joseph, Matthias Fritz \& Mark Wenthe, 15-20. Berlin: Walter de Gruyter.

Kuhn, Adalbert. 1853. Ueber die durch nasale erweiterten Verbalstämme. Zeitschrift für vergleichende Sprachforschung 2: 455-471.

Lakoff, George. 1987. Women, Fire, and Dangerous Things: What Categories Reveal about the Mind. Chicago: University of Chicago Press.

Lehmann, Winfred P. 1974. Proto-Indo-European Syntax. Austin: University of Texas Press.

Lehmann, Winfred P. 1993. Theoretical Bases of Indo-European Linguistics, London: Routledge.

Lehmann, Winfred P. 1994. Residues of Pre-Indo-European Active Structure and their Implications for the Relationships among the Dialects. Innsbruck: Innsbrucker Beiträge zur Sprachwissenschaft.

Lightfoot, David W. 1979. Principles of Diachronic Syntax. Cambridge: Cambridge University Press.

Lightfoot, David W. 198o. On Reconstructing a Proto-Syntax. Linguistic Reconstruction and Indo-European Syntax, ed. by Paolo Ramat, 27-45. Amsterdam: John Benjamins.

Lightfoot, David W. 1999. The Development of Language: Acquisition, Change and Evolution. Oxford: Blackwell.

Lightfoot, David W. 2002a. Myths and the Prehistory of Grammars. Journal of Linguistics 38(1): $113-136$.

Lightfoot, David W. 2002b. More Myths. Journal of Linguistics 38(3): 619-626. 
Lightfoot, David W. 2006. How New Languages Emerge. Cambridge: Cambridge University Press.

Mendoza, Julia. 1998. Sintaxis. Manual de lingüística indoeuropea III, ed. by Francisco R. Adrados, Alberto Bernabé \& Julia Mendoza, 141-246. Madrid: Ediciones Clásicas.

Mengden, Ferdinand von. 2008. Reconstructing Complex Structures: A Typological Perspective. Principles of Syntactic Reconstruction, ed. by Gisella Ferraresi \& Maria Goldbach, 97-119. Amsterdam: John Benjamins.

Michaelis, Laura A. \& Josef Ruppenhofer. 2001. Beyond Alternations: A Constructional Model of the German Applicative Pattern. Stanford: cs LI Publications.

Miller, D. Gary 1975. Indo-European: vso, sov, svo, or all three? Lingua 37: 31-52.

Mithun, Marianne. 2006. Integrating Approaches to Diversity: Argument Structure on the $N W$ Coast. Diversity in Language: Perspectives and Implications, ed. by Yoshiko Matsumoto, David Oshima, Orrin Robinson \& Peter Sells, 9-36. Stanford, CA: csLI. Mithun, Marianne. 2012. Core Argument Patterns and Deep Genetic Relations: Hierarchical Systems in Northern California. Argument Structure and Grammatical Relations: A Crosslinguistic Typology, ed. by Pirkko Suihkonen, Bernard Comrie \& Valery Solovyev, 258-294. Amsterdam: John Benjamins.

Nunberg, Geoffrey, Ivan A. Sag \& Thomas Wasow. 1994. Idioms. Language 70: 491-538. Osthoff, Hermann \& Karl Brugman. 1878. Morphologische Untersuchungen auf dem Gebiet der indogermanischen Sprachen 1. Leipzig: Hirzel.

Pedersen, Holger. 1907. Neues und nachträgliches. Zeitschrift für vergleichende Sprachforschung 40: 129-217.

Penney, John. 200o. Review of Berthold Delbrücky la sintaxis indoeuropea hoy. Actas del coloquio de la Indogermanische Gesellschaft, ed. by Emilio Crespo \& José L. García Ramón, Madrid, Ediciones de la UAM \& Wiesbaden, Dr. Ludwig Reichert Verlag. 1997. Kratylos 45: 29-35.

Pires, Acrisio \& Sarah G. Thomason. 2008. How Much Syntactic Reconstruction is Possible? Principles of Syntactic Reconstruction, ed. by Gisela Ferraresi \& Maria Goldbach, 27-72. Amsterdam: John Benjamins.

Pooth, Roland, Peter Alexander Kerkhof, Leonid Kulikov \& Jóhanna Barðdal. 2019. The Origin of Non-Canonical Case Marking of Subjects in Proto-Indo-European: Accusative, Ergative, or Semantic Alignment. Indogermanische Forschungen 124: $245^{-263 .}$

Rankin, Robert. 1992. Review of Greenberg. 1987. International Journal of American Linguistics 58: 324-351.

Ringe, Donald. 1992. On Calculating the Factor of Chance in Language Comparison.

Transactions of the American Philosophical Society 82: 1-110.

Roberts, Ian. 2007. Diachronic Syntax. Oxford: Oxford University Press. 
Rumsey, Alan. 1987a. Was Proto-Indo-European an Ergative Language? Journal of Indo-European Studies 15: 19-37.

Rumsey, Alan. 1987b. The Chimera of Proto-Indo-European Ergativity: Lessons for Historical Syntax. Lingua 71: 297-318.

Seržant, Ilja. 2015. An Approach to Syntactic Reconstruction. Perspectives on Historical Syntax, ed. by Carlotta Viti, 117-154. Amsterdam: John Benjamins.

Szemerényi, Oswald. 1996. Introduction to Indo-European Linguistics. Oxford: Oxford University Press.

Thurneysen, Rudolf. 1885. Der indogermanische Imperativ. Zeitschrift für vergleichende Sprachforschung 27(2): 172-180.

Tomasello, Michael. 2003. Constructing a Language. Cambridge, Mass: Harvard University Press.

Traugott, Elizabeth Closs \& Graeme Trousdale. 2013. Constructionalization and Constructional Change. Oxford: Oxford University Press.

Uhlenbeck, Christianus C. 1901. Agens und Patiens im Kasussystem der indogermanischen Sprachen. Indogermanische Forschungen 12: 170-171.

Vaillant, André. 1936. L'ergatif indo-européen. Bulletin de la Société de Linguistique de Paris 37: 93-108.

Vajda, Edward. 2018. Dene-Yeniseian: Progress and Unanswered Questions. Diachronica 35(2): $277-295$.

Vázquez-González, Juan G. \& Jóhanna Barðdal. 2019. Reconstructing the Ditransitive Construction for Proto-Germanic: Gothic, Old English and Old Norse-Icelandic. Folia Linguistica Historica 40(2): 555-620.

Villar, Francisco. 1983. Ergatividad, acusatividad y género en la familia lingüística indoeuropea. Salamanca: Universidad de Salamanca.

Vincent, Nigel, \& Ian Roberts. 1999. Remarks on Syntactic Reconstruction. A paper delivered at the Annual Meeting of the Deutsche Gesellschaft für Sprachwissenschaft, University of Konstanz.

Viti, Carlotta. 2015. Historical Syntax: Problems, Materials, Methods, Hypotheses. Perspectives on Historical Syntax, ed. by Carlotta Viti, 3-31. Amsterdam:John Benjamins.

Wackernagel, Jacob. 1892. Ueber ein Gesetz der indogermanischen Wortstellung. Indogermanische Forschungen 1: 333-436.

Walkden, George. 20o9. The Comparative Method in Syntactic Reconstruction, University of Cambridge M. A. thesis.

Walkden, George. 2013. The Correspondence Problem in Syntactic Reconstruction. Diachronica 30: 95-122.

Walkden, George. 2014. Syntactic Reconstruction and Proto-Germanic. Oxford: Oxford University Press. 
Watkins, Calvert. 1964. Preliminaries to the Reconstruction of Indo-European Sentence Structure. Proceedings of the IX International Congress of Linguists, ed. by H. G. Lunt, 1035-1045. The Hague: Mouton.

Watkins, Calvert. 1976. Towards Proto-Indo-European Syntax: Problems and Pseudo-Problems. Papers from the Parasession on Functionalism, ed. by S. B. Steever, C. A. Walker \& S. S. Mufwene, 205-326. Chicago: Chicago Linguistic Society.

Watkins, Calvert. 1995. How to Kill a Dragon: Aspects of Indo-European Poetics. Oxford: Oxford University Press.

Wichmann, Søren. 2008. The Study of Semantic Alignment: Retrospect and the State of the Art. The Typology of Semantic Alignment, ed. by M. Donohue \& S. Wichmann, 3-23. Oxford: Oxford University Press.

Willi, Andreas. 2018. Origins of the Greek Verb. Cambridge: Cambridge University Press.

Willis, David. 2011. Reconstructing Last Week's Weather: Syntactic Reconstruction and Brythonic Free Relatives. Journal of Linguistics 47: 407-446.

Winter, Werner.1984. Reconstructional Comparative Linguistics and the Reconstruction of the Syntax of Undocumented Stages in the Development of Languages and Language Families. Historical Syntax, ed. by J. Fisiak, 613-625. The Hague: Mouton. 